\title{
Controle microbiológico de drogas vegetais comercializadas na região central do Rio Grande do Sul
}

\author{
GINDRI, A. L. ${ }^{1 *} ;$ LAPORTA, L. V. ${ }^{2}$; SANTOS, M. R. ${ }^{2}$ \\ ${ }^{1}$ Universidade Federal de Santa Maria - UFSM, Departamento de Farmácia Industrial, Avenida Roraima, 1000, Cidade \\ Universitária, Bairro Camobi, CEP: 97105-900-Santa Maria-Brasil *amandagindri@terra.com.br ${ }^{2}$ Centro Universitário \\ Franciscano-UNIFRA, Laboratório de Controle de Qualidade e Equivalência Farmacêutica, Rua dos Andradas, \\ 1614, Sala S011, Bairro Centro, CEP: 97010-032, Santa Maria-Brasil
}

\begin{abstract}
RESUMO: O objetivo deste trabalho foi analisar a qualidade microbiológica de 40 amostras de matérias-primas de fitoterápicos coletadas de farmácias de manipulação da região central Rio Grande do Sul. Foram realizados os testes de contagem de microrganismos viáveis e pesquisa e identificação de patógenos, ambos de acordo com a Farmacopéia Brasileira. Os resultados obtidos mostraram que há presença de microrganismos nas amostras, entretanto, em nenhuma delas, o valor de UFC $\mathrm{g}^{-1}$ ultrapassou o limite estabelecido para fitoterápicos na Farmacopéia Britânica, tanto para bactérias como para fungos. No teste de pesquisa e identificação de patógenos comprovou-se que não havia a presença de Pseudomonas aeruginosa, Salmonella sp, Staphylococcus aureus e Escherichia coli, nas amostras analisadas. As amostras estão aptas a serem comercializadas, pois todas estavam dentro dos limites especificados, e foram aprovadas pelo teste de controle de qualidade microbiológico.
\end{abstract}

Palavras-chave: controle de qualidade microbiológico, farmácia de manipulação, plantas medicinais

\begin{abstract}
Microbiological control of medicinal drugs commercialized in the central region of Rio Grande do Sul, Brazil. The aim of this study was to analyze the microbiological quality of 40 samples of raw material for herbal medicines collected from compounding pharmacies in the center of Rio Grande do Sul, Brazil. Count of viable microorganisms and search and identification of pathogens were performed, both according to the Brazilian Pharmacopoeia. Results showed that there were microorganisms in the samples; however, in none of them, the value of CFU g-1 was above the limit established for herbal medicines by the British Pharmacopoeia, both for bacteria and fungi. The search and identification of pathogens indicated that there was no Pseudomonas aeruginosa, Salmonella sp, Staphylococcus aureus and Escherichia coli in the analyzed samples. The samples can be commercialized because all of them were within the allowed limits and were approved in the test for microbiological quality control.
\end{abstract}

Key words: microbiological quality control, compounding pharmacy, medicinal plants

\section{INTRODUÇÃO}

Atualmente, a sociedade tem buscado hábitos mais saudáveis de vida na natureza, o que, associado ao alto preço dos medicamentos, tem levado a aumento da utilização e produção de medicamentos fitoterápicos (Rocha et al., 2004). No ano de 2000 , os produtos a base de plantas medicinais movimentaram cerca de 30 bilhões de dólares. A Organização Mundial da Saúde estima que $80 \%$ das pessoas dependem da medicina tradicional (Melo et al., 2007).

Apesar dos grandes avanços da indústria farmacêutica, a utilização dessa terapia alternativa vem crescendo, o que aumenta a responsabilidade das agências regulatórias e dos fabricantes, pois devem assegurar a qualidade e eficácia terapêutica desses produtos (Satomi et al., 2005). Segundo a legislação atual, fitoterápico é um medicamento obtido empregando-se exclusivamente matériasprimas ativas vegetais. É caracterizado pelo conhecimento da eficácia e dos riscos do uso, assim como pela reprodutibilidade e constância de qualidade. Não se considera medicamento

Recebido para publicação em 20/02/2011

Aceito para publicação em 03/04/2012

Rev. Bras. PI. Med., Botucatu, v.14, n.3, p.563-570, 2012. 
fitoterápico aquele que, na composição, inclua substâncias ativas isoladas, de qualquer origem, nem as associações destas com extratos vegetais (Anvisa, 2010).

As matérias-primas de origem natural são mais susceptíveis a apresentarem problemas de contaminação. Fatores como poluição na água de irrigação, atmosfera, solo, condições da coleta, manipulação, secagem e estocagem são importantes e devem ser considerados, por permitirem altos níveis de contaminação microbiana, por vezes patogênica (Bugno et al., 2005). Os microrganismos, de maneira geral, exigem condições favoráveis para o crescimento, o que torna algumas matérias-primas livres de contaminação ou, pelo contrário, muito susceptíveis. Estas últimas podem tornar-se substrato para o crescimento microbiano, uma vez que podem ser utilizadas como fonte de carboidratos, aminoácidos, proteínas, vitaminas, sais orgânicos, água, entre outros (Pinto et al., 2003).

As preparações de drogas vegetais, geralmente são oriundas de plantas coletadas, secas e empacotadas, sem muitos cuidados de higiene e controle sanitário. Os produtos destinados às farmácias de manipulação, por serem distribuídos em pequena quantidade, ainda passam pelo processo de fracionamento, podendo carrear partículas viáveis e não-viáveis, aumentando ainda mais a carga microbiana (Furlaneto et al., 2003; Bugno et al., 2005; Souza et al., 2006).

As farmácias de manipulação, também chamadas magistrais, têm se mostrado uma alternativa quando o paciente necessita de doses personalizadas de determinado medicamento, o que resultou num crescente aumento da procura por medicamentos manipulados. Outro fator que justifica esse crescimento é o custo desses medicamentos, que em geral, são mais baratos que os industrializados. Entretanto, o controle de qualidade das matérias-primas e dos produtos acabados é grande obstáculo a ser superado (Furlaneto et al., 2003; Bugno et al., 2005; Souza et al., 2005).

O número de estabelecimentos fornecedores destes serviços também vem aumentando. De acordo com dados fornecidos pelo Conselho Federal de Farmácia, em dezembro de 2003 existiam, no Brasil, 3.958 farmácias de manipulação (C.F.F., 2005), e em 2006 estas já eram mais de cinco mil farmácias magistrais (Anvisa, 2006).

A qualidade microbiológica das matériasprimas vegetais apresenta, geralmente, índices de contaminação microbiana acima de níveis internacionalmente aceitos para os medicamentos (Souza et al., 2006). Conforme Pinto et al. (2003), as drogas vegetais brutas normalmente têm contaminação fúngica de $10^{4} \mathrm{~g}^{-1} \mathrm{e}$ bacteriana de $10^{5}$ $\mathrm{g}^{-1}$, considerando os contaminantes mais comuns $\mathrm{o}$
Aspergillus e Penicillium, esporos do gênero Bacillus e algumas vezes Micrococcus e Staphylococcus spp. Devido às exigências da Agência Nacional de Vigilância Sanitária frente aos laboratórios de manipulação para que estes realizassem o controle microbiológico das matérias-primas de origem vegetal, e ao fato de que a contaminação microbiana pode levar ao comprometimento do desempenho do produto e, consequentemente, a prejuízos a saúde do paciente, esse trabalho teve como objetivo avaliar a qualidade microbiológica das matérias-primas de drogas vegetais comercializados na região de Santa Maria.

\section{MATERIALE MÉTODO}

\section{Amostras}

Foram avaliadas 40 amostras de matériasprimas vegetais (drogas in natura) comercializadas na região central do Rio Grande do Sul. As amostras, descritas a seguir, foram escolhidas pela disponibilidade comercial e popularidade de uso, Agar agar póGellidium cartilagineum (Linné) Gaillon (Gelidiaceae), Gracilaria confervoides (Linné) Greville (Sphaeroccaceae) - 2 lotes; Alcachofra Extrato seco Cynara scolymus (Asteraceae) - 4 lotes; Aloína pó Aloe vera (Liliaceae) - 1 lote; Boldo extrato seco Peumus boldus (Monimiaceae) - 1 lote; Carqueja extrato seco - Baccharis trimera (Less.) DC. (Asteraceae) - 1 lote; Cáscara Sagrada extrato seco- Rhamnus purshiana (Rhamnaceae) - 1 lote; Castanha da Índia extrato seco - Aesculus hippocastanum (Hipocastanaceae) - 3 lotes; Caraluma extrato seco Caraluma fimbriata (Asclepiadácea) - 1 lote; Catuaba pó - Anemopaegma mirandum (Bignoniaceae) - 1 lote; Cavalinha extrato seco - Equisetum sp (Equisetaceae) 1 lote; Centella-asiática pó - Hydrocolite asiatica L. (Centella asiática Urban) (H. hebecarpa A.) (Umbiliferas)1 lote; Chá Branco Extrato seco - Camellia sinensis (Theaceae) - 1 lote; Espinheira-santa extrato secoMaytenus ilicifolia (Celastraceae) - 1 lote; Fucusvesiculosos extrato seco - Fucus vesiculosus $\mathrm{L}$. (Fucaceae) - 1 lote; Garcínia pó - Garcínia cambogia (Gutiferáceas ou Clusiáceas) - 1 lote; Ginkgo-biloba extrato seco - Ginkgo biloba L. (Ginkgoácea) - 3 lotes; Ginseng-coreano extrato seco - Panax ginseng C.A. Mey (Araliaceae) - 1 lote; Guaraná pó - Paullinia cupana Kunth (Sapindaceae) - 1 lote; Hipérico extrato seco - Hypericum perforatum (Hipericaceae) - 2 lotes; Isoflavona pó - Glycine max (L.) Merr. (Fabaceae) - 2 lotes; Maracujá extrato seco - Passiflora alata Dryand (Passifloraceae) - 2 lotes; Panax-ginseng extrato seco - Panax ginseng C.A. Mey (Araliaceae) - 1 lote; Pata-de-vaca pó - Bauhinia forficata Link. (Fabaceae) 1 lote; Quebra-pedra extrato seco - Phyllanthus urinaria L (Euphorbiaceae) - 1 lote; Rutina pó - Ruta

Rev. Bras. Pl. Med., Botucatu, v.14, n.3, p.563-570, 2012. 
graveolens L. (Rutaceae) - 2 lotes; Sene extrato seco Cássia senna e Cássia angustifólia (Leguminosae) 1 lote; Unha-de-gato extrato seco - Uncaria tomentosa ( Wild) DC. (Rublaceae) - 1 lote; Valeriana extrato seco - Valeriana officinalis L. (Valerianaceae) - 1 lote.

\section{Contagem total de microrganismos viáveis}

Os testes de contagem total de microrganismos viáveis foram realizados conforme a Farmacopéia Brasileira, parte I (1988). Para estes testes porções de $10 \mathrm{~g}$ de amostra foram transferidas para balões volumétricos de $100 \mathrm{~mL}$ e diluídas com tampão fosfato $\mathrm{pH} 7,2$ (1/10). Transferiu-se $10 \mathrm{~mL}$ da solução $1 / 10$ para balão volumétrico de $100 \mathrm{~mL}$ e completou-se o volume com o mesmo diluente (1/ 100). Diluiu-se $10 \mathrm{~mL}$ da solução $1 / 100$ para balão volumétrico de $100 \mathrm{~mL}$ e completou-se o volume com o tampão fosfato $\mathrm{pH} 7,2$ (1/1.000).

Para a execução do método de contagem em placas para bactérias adicionou-se $1 \mathrm{~mL}$ da amostra e $15 \mathrm{~mL}$ do Meio I (Ágar caseína-soja) liquefeito a $45^{\circ} \mathrm{C}$, em placas de Petri $(100 \times 20 \mathrm{~mm})$. A amostra foi diluída de maneira que não ultrapassasse 300 colônias por placa. Foram preparadas duas placas de Petri para cada diluição $(1 / 10,1 / 100,1 / 1000)$ e estas foram incubadas a 30 $35^{\circ} \mathrm{C}$, por 4 dias.

Para a execução do método de contagem em placas para fungos adicionou-se $1 \mathrm{~mL}$ da amostra e $15 \mathrm{~mL}$ do Meio II (Ágar sabourand dextrose) liquefeito a $45^{\circ} \mathrm{C}$, em placas de Petri $(100 \times 20 \mathrm{~mm})$. A amostra foi diluída de maneira que não ultrapassasse 100 colônias por placa. Foram preparadas duas placas de Petri para cada diluição $(1 / 10,1 / 100,1 / 1000)$ e estas foram incubadas a $20-25^{\circ} \mathrm{C}$, por 7 dias.

Após a incubação foi efetuada a média aritmética do número de colônias por placa e a partir dos valores, obteve-se o número de microrganismos por grama, multiplicando-se pela diluição usada. Os resultados foram expressos em unidades formadoras de colônias (UFC).

\section{Pesquisa e identificação de patógenos}

O método de pesquisa e identificação de patógenos foi realizado conforme descrito na Farmacopéia Brasileira, parte I (1988).

Em primeiro lugar foi realizado o enriquecimento não seletivo nas amostras que obtiveram crescimento no meio I. Neste teste transferiu-se $3,33 \mathrm{~g}$ da amostra para frasco contendo $100 \mathrm{~mL}$ de caldo de enriquecimento e incubou-se, a $30-35^{\circ} \mathrm{C}$, durante 48 horas.

Após este primeiro procedimento foram realizadas as etapas da fase seletiva, onde quando resultado foi positivo nos meios seletivos, se prosseguia os testes confirmatórios respectivos. A seguir estão descritos os testes seletivos e confirmatórios para cada microrganismo.

\section{Pseudomonas aeruginosa}

Transferiu-se, com auxílio de alça de platina, o material enriquecido no meio não seletivo, para placa de Petri contendo ágar cetrimida, usando o método de estrias em superfície. A placa foi incubada a $36^{\circ} \mathrm{C}$, durante 48 horas. Quando houve crescimento de colônias neste meio, procedeu-se aos seguintes testes confirmatórios apresentados na Tabela 1.

\section{Staphylococcus aureus}

Transferiu-se, com auxílio de alça de platina, o material enriquecido no meio não seletivo, para placa de Petri contendo ágar sal manitol-vermelho de fenol, usando o método de estrias em superfície. A placa foi incubada a $36^{\circ} \mathrm{C}$, durante 48 horas. Quando houve crescimento de colônias neste meio, procedeu-se aos seguintes testes confirmatórios apresentados na Tabela 2.

TABELA 1. Testes confirmatórios para Pseudomonas aeruginosa.

\begin{tabular}{|c|c|c|c|}
\hline $\begin{array}{c}\text { Teste } \\
\text { confirmatório }\end{array}$ & Análise & $\begin{array}{c}\text { Temperatura / } \\
\text { Tempo de incubação }\end{array}$ & Resultado \\
\hline $\begin{array}{l}\text { Citocromo } \\
\text { oxidase }\end{array}$ & $\begin{array}{l}\text { Adicinou-se uma gota de solução } \\
\text { aquosa a } 1 \%(\mathrm{p} / \mathrm{V}) \text { de cloridrato de } \\
n, n \text {-dimetil-p-fenilenodiamina na } \\
\text { colônia suspeita. }\end{array}$ & $\begin{array}{l}\text { Temperatura } \\
\text { ambiente - sem } \\
\text { incubação }\end{array}$ & $\begin{array}{l}\text { Analisou-se se houve a } \\
\text { coloração da colônia. }\end{array}$ \\
\hline $\begin{array}{l}\text { Produção de } \\
\text { fluoresceína }\end{array}$ & $\begin{array}{l}\text { Incubou-se colônia em tubo } \\
\text { contendo ágar inclinado para } \\
\text { detecção de fluoresceína. }\end{array}$ & $30-37^{\circ} \mathrm{C}-24$ horas & $\begin{array}{l}\text { Analisou-se se houve a } \\
\text { produção de fluoresceína } \\
\text { na luz ultravioleta de } 328 \text { a }\end{array}$ \\
\hline $\begin{array}{l}\text { Crescimento } \\
\text { à } 41^{\circ} \mathrm{C}\end{array}$ & $\begin{array}{l}\text { Incubou-se colônia em tubo } \\
\text { contendo ágar inclinado de infusão } \\
\text { cérebro e coração. }\end{array}$ & $41^{\circ} \mathrm{C}-48$ horas & $\begin{array}{l}210 \mathrm{~nm} \\
\text { Analisou-se se houve } \\
\text { crescimento microbiano }\end{array}$ \\
\hline
\end{tabular}

Rev. Bras. PI. Med., Botucatu, v.14, n.3, p.563-570, 2012. 
TABELA 2. Testes confirmatórios para Staphylococcus aureus.

\begin{tabular}{|c|c|c|c|}
\hline $\begin{array}{c}\text { Teste } \\
\text { confirmatório }\end{array}$ & Análise & $\begin{array}{c}\text { Temperatura } / \\
\text { Tempo de incubação }\end{array}$ & Resultado \\
\hline $\begin{array}{l}\text { Coloração } \\
\text { de Gram }\end{array}$ & $\begin{array}{l}\text { Transferiu-se a colônia suspeita do } \\
\text { meio seletivo para lâmina de } \\
\text { microscopia e procedeu-se aos } \\
\text { testes de coloração de Gram. }\end{array}$ & $\begin{array}{l}\text { Temperatura } \\
\text { ambiente- } \\
\text { sem incubação }\end{array}$ & $\begin{array}{l}\text { Analisou-se os grupamentos } \\
\text { no microscópio, para identificar } \\
\text { se eram Gram-positivos. }\end{array}$ \\
\hline Coagulase + & $\begin{array}{l}\text { Inocularam-se as colônias suspeitas } \\
\text { em liofilizado de plasma de coelho } \\
\text { reconstituído. }\end{array}$ & $\begin{array}{l}\text { Banho-maria a } 30- \\
37^{\circ} \mathrm{C}-2,4 \text { e } 24 \text { horas }\end{array}$ & $\begin{array}{l}\text { Observou-se se houve ou } \\
\text { não a formação de gel. }\end{array}$ \\
\hline Desoxirribonuclease & $\begin{array}{l}\text { Inoculou-se a colônia suspeita em } \\
\text { tubo contendo agar para teste de } \\
\text { desoxirribonuclease com verde de } \\
\text { metila inclinado. }\end{array}$ & $30-37^{\circ} \mathrm{C}-18$ horas & $\begin{array}{l}\text { Analisou-se se houve } \\
\text { crescimento microbiano. } \\
\text { Comparou-se com um } \\
\text { controle positivo. }\end{array}$ \\
\hline
\end{tabular}

\section{Salmonella sp.}

Transferiu-se, com auxílio de alça de platina, o material enriquecido no meio não seletivo, para placa de Petri contendo ágar verde brilhante de fenol, usando o método de estrias em superfície. A placa foi incubada a $36^{\circ} \mathrm{C}$, durante 48 horas. Inoculou-se uma colônia suspeita em $100 \mathrm{~mL}$ de caldo digesto pancreático de caseína e incubou-se a $30-37^{\circ} \mathrm{C}$ de 24 a 48 horas, adicionando-se após a incubação 0,5 $\mathrm{mL}$ do Reagente de Kovak. Reação negativa é típica de Salmonella sp. Quando houve crescimento de colônias no meio ágar verde brilhante de fenol, procedeu-se aos seguintes testes confirmatórios apresentados na Tabela 3.

\section{Escherichia coli}

Transferiu-se, com auxílio de alça de platina, o material enriquecido no meio não seletivo, para placa de Petri contendo ágar Mac Conkey, usando o método de estrias em superfície. A placa foi incubada de $30-37^{\circ} \mathrm{C}$, durante 48 horas. Quando houve crescimento de colônias neste meio, as mesmas foram transferidas para tubo de ensaio contendo ágar peptona-ferro, perfurando-se a base não inclinada com fio reto, passando-se pela superfície inclinada e a placa foi incubada na temperatura entre $30-37^{\circ} \mathrm{C}$, durante 24 horas. Outra colônia foi transferida para placa de Petri contendo ágar de eosina-cloreto de metiltionínio (EMB) e incubada por 24 horas, a 30$37^{\circ} \mathrm{C}$. Quando o resultado foi positivo nos ensaios anteriores, procedeu-se aos seguintes testes confirmatórios apresentados na Tabela 4.

\section{RESULTADO E DISCUSSÃO}

Contagem total de microrganismos viáveis A contagem total de microrganismos viáveis é um método capaz de determinar o número de bactérias e fungos presentes em produtos e matériasprimas não-estéreis. O método consiste na contagem da população de microrganismos que apresentem

TABELA 3. Testes confirmatórios para Salmonella sp.

\begin{tabular}{|c|c|c|c|}
\hline $\begin{array}{c}\text { Teste } \\
\text { confirmatório }\end{array}$ & Análise & $\begin{array}{c}\text { Temperatura / } \\
\text { Tempo de incubação }\end{array}$ & Resultado \\
\hline $\begin{array}{l}\text { Ágar tríplice } \\
\text { açúcar-ferro }\end{array}$ & $\begin{array}{l}\text { Incubou-se uma colônia suspeita em tubo } \\
\text { contendo ágar tríplice açúcar-ferro. }\end{array}$ & $30-37^{\circ} \mathrm{C}-24$ horas & $\begin{array}{l}\text { Analisou-se se houve } \\
\text { alteração de cor no meio. }\end{array}$ \\
\hline $\begin{array}{l}\text { Lisina- } \\
\text { descarboxilase }\end{array}$ & $\begin{array}{l}\text { Incubou-se uma colônia suspeita para um } \\
\text { tubo com ágar de lisina-ferro inclinado. }\end{array}$ & $30-37^{\circ} \mathrm{C}-24$ horas & $\begin{array}{l}\text { Analisou-se se houve } \\
\text { alteração de cor no meio. }\end{array}$ \\
\hline $\begin{array}{l}\text { Crescimento a } \\
\text { partir de citrato } \\
\text { como única fonte } \\
\text { de carbono }\end{array}$ & $\begin{array}{l}\text { Incubou-se uma colônia suspeita para tubo } \\
\text { com ágar citrato de Simmons inclinado. }\end{array}$ & $30-37^{\circ} \mathrm{C}-4$ dias & $\begin{array}{l}\text { Analisou-se se houve } \\
\text { alteração de cor no meio. }\end{array}$ \\
\hline Urease & $\begin{array}{l}\text { Incubou-se uma colônia suspeita } \\
\text { em tubo com ágar uréia inclinado. }\end{array}$ & $30-37^{\circ} \mathrm{C}-4$ dias & $\begin{array}{l}\text { Analisou-se a presença } \\
\text { de urease. }\end{array}$ \\
\hline $\begin{array}{l}\text { Fermentação } \\
\text { da Lactose }\end{array}$ & $\begin{array}{l}\text { Incubou-se uma colônia suspeita } \\
\text { em tubo com caldo de lactose. }\end{array}$ & $30-37^{\circ} \mathrm{C}-24$ horas & $\begin{array}{l}\text { Analisou-se se houve } \\
\text { alteração no meio. }\end{array}$ \\
\hline
\end{tabular}

Rev. Bras. PI. Med., Botucatu, v.14, n.3, p.563-570, 2012. 
TABELA 4. Testes confirmatórios para Escherichia coli.

\begin{tabular}{|c|c|c|c|}
\hline $\begin{array}{c}\text { Teste } \\
\text { confirmatório }\end{array}$ & Análise & $\begin{array}{c}\text { Temperatura I } \\
\text { Tempo de incubaçãc }\end{array}$ & Resultado \\
\hline $\begin{array}{l}\text { Ágar Tríplice } \\
\text { Açúcar-Ferro }\end{array}$ & $\begin{array}{l}\text { Incubou-se uma colônia suspeita do } \\
\text { meio EMB em tubo com ágar tríplice } \\
\text { açúcar-ferro inclinado. }\end{array}$ & $30-37^{\circ} \mathrm{C}-24$ horas & $\begin{array}{l}\text { Analisou-se o crescimento } \\
\text { microbiano e a formação de gás. }\end{array}$ \\
\hline Teste de Indol & $\begin{array}{l}\text { Incubou-se uma colônia suspeita do } \\
\text { meio EMB em tubo de ensaio contendo } \\
\text { caldo digesto pancreático. }\end{array}$ & $30-37^{\circ} \mathrm{C}-48$ horas & $\begin{array}{l}\text { Adicionou-se o } 0,5 \mathrm{~mL} \text { de } \\
\text { reagente de Kovac, agitando o } \\
\text { tubo suavemente. Verificou-se a } \\
\text { coloração formada. }\end{array}$ \\
\hline $\begin{array}{l}\text { Teste de } \\
\text { Vermelho de } \\
\text { Metila }\end{array}$ & $\begin{array}{l}\text { Incubou-se uma colônia do meio EMB } \\
\text { em tubo com caldo vermelho de metila } \\
\text { Voges-Proskauer. }\end{array}$ & $\begin{array}{c}30-37^{\circ} \mathrm{C}-18 \text { a } 48 \\
\text { horas }\end{array}$ & $\begin{array}{l}\text { Adicionou-se } 15 \text { gotas do } \\
\text { indicador vermelho de metila. } \\
\text { Verificou-se a coloração } \\
\text { formada. }\end{array}$ \\
\hline $\begin{array}{l}\text { Teste de } \\
\text { Voges- } \\
\text { Proskauer }\end{array}$ & $\begin{array}{l}\text { Incubou-se uma colônia do meio EMB } \\
\text { em tubo com caldo vermelho de metila } \\
\text { Voges-Proskauer. }\end{array}$ & $\begin{array}{c}30-37^{\circ} \mathrm{C}-24 \\
\text { horas }\end{array}$ & $\begin{array}{l}\text { Adicionou-se } 4 \mathrm{~mL} \text { do reagente } \\
\text { de Voges-Proskauer, incubando } \\
\text { novamente, de } 35 \text { a } 37^{\circ} \mathrm{C} / 1 \text { hora. } \\
\text { Verificou-se a coloração } \\
\text { formada. }\end{array}$ \\
\hline $\begin{array}{l}\text { Crescimento a } \\
\text { partir de Citrato } \\
\text { como única fonte } \\
\text { de Carbono }\end{array}$ & $\begin{array}{l}\text { Incubou-se uma colônia do meio EMB } \\
\text { em tubo com ágar citrato Simmons } \\
\text { inclinado. }\end{array}$ & $30-37^{\circ} \mathrm{C}-4$ dias & $\begin{array}{l}\text { Analisou-se o crescimento } \\
\text { microbiano. }\end{array}$ \\
\hline
\end{tabular}

crescimento visível em 4 dias, em ágar caseína soja (Meio I) a $30-35^{\circ} \mathrm{C}$ e em ágar sabouraud-dextrose (Meio II) a $20-25^{\circ} \mathrm{C}$, em 7 dias (Farmacopéia Brasileira, 1988).

Foi evidenciado crescimento bacteriano nas seguintes amostras: Agar-agar - lote 1 (650 UFC g ${ }^{-1}$ ); Alcachofra - lote 2 (10 UFC g-1 ); Alcachofra - lote 3 (30 UFC g-1 ); Aloína (70 UFC g ${ }^{-1}$ ); Castanha-da-Índia Lote 1 (140 UFC g $\left.{ }^{-1}\right)$; Castanha-da-Índia - lote 3 (40UFC g ${ }^{-1}$ ); Catuaba (55 UFC g ${ }^{-1}$ ); Caraluma (567 UFC $\mathrm{g}^{-1}$ ); Garcínia (30 UFC g ${ }^{-1}$ ); Isoflavona - lote 1 (10 UFC $\mathrm{g}^{-1}$ ); Maracujá - lote 1 (1833 UFC g ${ }^{-1}$ ); Maracujá - lote 2 (407 UFC g ${ }^{-1}$ ) e Unha-de-gato (487 UFC g ${ }^{-1}$ ). As outras amostras obtiveram resultados $<10 \mathrm{UFC} \mathrm{g}^{-1}$.

Para o meio II, foram evidenciados crescimentos nas placas contendo as amostras de: Agar-agar - lote 1 (900 UFC g ${ }^{-1}$ ); Agar-agar - lote 2 (10 UFC g-1 ); Alcachofra - lote 1 (10 UFC g-1 ); Alcachofra lote 4 (10 UFC g ${ }^{-1}$ ); Boldo (55 UFC g ${ }^{-1}$ ); Castanha-daíndia - lote 1 (413 UFC g-1 ); Castanha-da-índia - lote 2 (10 UFC g ${ }^{-1}$ ); Catuaba (55 UFC g ${ }^{-1}$ ); Cavalinha (100 UFC g ${ }^{-1}$ ); Centella-asiática (40 UFC g ${ }^{-1}$ ); Caraluma (20 UFC g-1 ); Espinheira-santa (505 UFC g ${ }^{-1}$ ); Fuccusvesiculosos (500 UFC g-1 ${ }^{-1}$; Castanha-da-índia - lote 1 (550 UFC g-1 ); Hipérico - lote 1 (10 UFC g ${ }^{-1}$ ); Isoflavona lote 1 (10 UFC g ${ }^{-1}$ ); Isoflavona - lote 2 (55 UFC g-1); Maracujá - lote 1 (460 UFC g ${ }^{-1}$ ); Maracujá - lote 2 (55 UFC g ${ }^{-1}$ ); Pata-de-vaca (10 UFC g-1 ); Quebra-pedra (550 UFC g ${ }^{-1}$ ); Rutina - lote 1 (20 UFC g ${ }^{-1}$ ); Rutina lote 2 (100 UFC g-1) e Unha-de-gato (50 UFC g-1). As outras amostras obtiveram o resultado <10 UFC g-1 para este teste.

Segundo a British Pharmacopoeia (2005), os limites permitidos para bactérias são de $10^{5} \mathrm{UFC}^{-1}$ e para fungos $10^{4}$ UFC g $^{-1}$. Nenhuma das amostras ultrapassou o limite máximo permitindo, estando todas aprovadas.

É importante ressaltar que, devido a carga microbiana já existente nas plantas pela flora saprófita e patogênica, além daqueles provenientes do solo, da água e do ar, algumas empresas distribuidoras de matérias primas utilizam procedimentos de descontaminação dos produtos (Satomi et al., 2005).

O procedimento de irradiação, utilizado por algumas distribuidoras, pode ter levado a aprovação de algumas amostras neste trabalho. No entanto, ao verificar os laudos das matérias primas foi observado que este processo para diminuição dos microrganismos foi realizado em somente 11 das 40 amostras, o que indica que este procedimento pode sim auxiliar na diminuição dos microrganismos viáveis nas drogas, no entanto não foi largamente utilizado pelas distribuidoras nestas matérias primas.

AAgência Nacional de Vigilância Sanitária regulamentou o registro de fitoterápicos na $\mathrm{RDC}$ no 48, de 16 de março de 2004, onde ressalta que os procedimentos de descontaminação requerem estudos relacionados à estabilidade dos princípios ativos dos produtos após a exposição a tais procedimentos.

Conforme Satomi e colaboradores (2005), o método de irradiação é eficaz na redução da carga 
microbiana para as drogas vegetais além de não causarem alterações no teor dos marcadores adotados. Podendo então ser considerado seguro para a redução de microrganismos sem afetar os metabólitos das plantas.

\section{Pesquisa e identificação de patógenos}

O teste de pesquisa e identificação de patógenos é um método que permite a detecção da presença de células viáveis de Salmonella sp., Escherichia coli, Pseudomonas aeruginosa e Staphylococus aureus, que devem estar ausentes em produtos farmacêuticos não estéreis.

As seguintes amostras analisadas apresentaram crescimento no meio I (não-seletivo): Ágar Ágar (lote 1); Alcachofra (lote 2); Alcachofra (lote 3); Aloína; Castanha-da-índia (lote 1); Castanha-daíndia (lote 3); Catuaba; Caraluma; Garcínia; Isofavona (lote 1); Maracujá (lote 1); Maracujá (lote 2) e Unhade-gato (lote 1).

As amostras que apresentaram crescimento no enriquecimento não seletivo, foram semeadas nos meios ágar cetrimida, ágar verde brilhante, ágar sal manitol vermelho de fenol e ágar Mac Conkey que são seletivos para Pseudomonas aeruginosa, Salmonella sp., Staphylococcus aureus e Escherichia coli, respectivamente. Das 13 amostras testadas, duas apresentaram crescimento no meio ágar cetrimida, três no ágar verde brilhante, sete no ágar manitol vermelho de fenol e uma no ágar Mac Conkey, sendo necessária a realização das fases confirmatórias, conforme demonstrado na Tabela 5.

\section{Fase confirmatória}

\section{Pseudomonas aeruginosa}

Para que o teste citocromo oxidase possa ser considerado positivo, as colônias suspeitas devem desenvolver coloração rósea, que passam a marrom, vermelho escuro e negro entre 10 e 30 minutos. Nenhuma das amostras analisadas obteve resultado positivo para esse teste. A fluoresceína pode ser detectada pela presença de fluorescência no ágar, quando observado à luz ultravioleta, no comprimento de onda entre 328 e $210 \mathrm{~nm}$. O crescimento a $41^{\circ} \mathrm{C}$ pode ser considerado positivo quando após o tempo de incubação, pode-se visualizar a presença de cepas. Ambas as amostras apresentaram resultado positivo para a presença de fluoresceína e crescimento $a 1^{\circ} \mathrm{C}$.

Conforme demonstrado na Tabela 6 , nenhuma das amostras apresentou resultado positivo para os três testes confirmatórios a que foram submetidos, motivo pelo qual podemos sugerir que não há presença de $P$ seudomonas aeruginosa, nos produtos analisados (Farmacopéia Brasileira, 1988).

\section{Staphylococcus aureus}

As sete amostras analisadas apresentaram resultado negativo para os testes confirmatórios de coloração de Gram e coagulase. No teste de coloração de Gram, identificam-se a presença de microrganismos Gram positivos, quando se visualiza, no microscópio, grupamentos semelhantes a cachos de uva. O teste de coagulase pode ser considerado positivo quando se observa a formação de gel no liofilizado de plasma de coelho. As amostras de alcachofra (lote 3), aloína, catuaba, garcínia e maracujá (lote 1) apresentaram a formação de uma zona incolor ao redor do crescimento das colônias, sendo o teste considerado positivo para esses cinco produtos.

Conforme demonstrado na Tabela 7, nenhuma das amostras apresentou resultado positivo para os três testes confirmatórios a que foram submetidos, não havendo a presença de Staphylococcus aureus, nos produtos (Farmacopéia Brasileira, 1988).

TABELA 5. Resultados obtidos na fase seletiva para a pesquisa e identificação de patógenos.

\begin{tabular}{|c|c|c|c|c|c|}
\hline & Amostras & $\begin{array}{c}\text { Ágar } \\
\text { cetrimida }\end{array}$ & $\begin{array}{l}\text { Ágar verde } \\
\text { brilhante }\end{array}$ & $\begin{array}{l}\text { Ágar sal manitol } \\
\text { vermelho de fenol }\end{array}$ & $\begin{array}{c}\text { Ágar Mac } \\
\text { Conkey }\end{array}$ \\
\hline Agar Agar - lote 1 & $x$ & & & $x$ & \\
\hline Alcachofra - lote 2 & & & $x$ & & \\
\hline Alcachofra - lote 3 & & & $x$ & & \\
\hline Aloína & & & $x$ & & \\
\hline Caraluma & & & $x$ & & \\
\hline Castanha-da-índia - lote 1 & & $x$ & & & \\
\hline \multicolumn{6}{|l|}{ Castanha-da-índia - lote 3} \\
\hline Catuaba & & & $x$ & & \\
\hline Garcínia & & & $x$ & & \\
\hline \multicolumn{6}{|l|}{ Isoflavona - lote 1} \\
\hline Maracujá - lote 1 & & $x$ & $x$ & & \\
\hline \multicolumn{6}{|l|}{ Maracujá - lote 2} \\
\hline Unha-de-gato & $x$ & $x$ & & & \\
\hline
\end{tabular}

Rev. Bras. PI. Med., Botucatu, v.14, n.3, p.563-570, 2012. 
TABELA 6. Resultados obtidos na fase confirmatória para Pseudomonas aeruginosa.

\begin{tabular}{cccc}
\hline Amostra & Citocromo oxidase & Fluoresceína & Crescimento a $41^{\circ} \mathbf{C}$ \\
\hline Agar-agar - lote 1 & negativo & positivo & positivo \\
Unha-de-gato - lote1 & negativo & positivo & positivo \\
\hline
\end{tabular}

TABELA 7. Resultados obtidos na fase confirmatória para Staphylococcus aureus.

\begin{tabular}{cccc}
\hline Amostras & Coloração de Gram & Coagulase & Desoxirribonuclease \\
\hline Alcachofra - lote 2 & negativo & negativo & negativo \\
Alcachofra - lote 3 & negativo & negativo & positivo \\
Aloína & negativo & negativo & positivo \\
Caraluma & negativo & negativo & negativo \\
Catuaba & negativo & negativo & positivo \\
Garcínia & negativo & negativo & positivo \\
Maracujá - lote 1 & negativo & negativo & positivo \\
\hline
\end{tabular}

\section{Salmonela sp.}

As amostras de castanha-da-índia (lote 1) e maracujá (lote 1) apresentaram reação alcalina, cor vermelha na parte superior e inclinada, e ácida, cor amarelada na base, sendo considerado positivo para o teste confirmatório de ágar tríplice açúcarferro. O teste de ágar de lisina-ferro é positivo quando a cor do meio se altera para púrpura (reação alcalina). Essa reação aconteceu em todos os produtos analisados.

Nenhuma das amostras foi positiva para o teste de citrato como única fonte de carbono, pois não houve a formação de colônias e a cor do meio, na parte inclinada, não mudou para azul. As amostras de castanha da índia (lote 1) e maracujá (lote 1), produziram urease e a de maracujá (lote 1) e unha-degato fermentaram a lactose, o que não é característico para a maioria das cepas de Salmonela sp.

Conforme demonstrado na Tabela 8, nenhuma das amostras apresentou resultados positivos para os cincos testes confirmatórios, o que indica a ausência de Salmonela sp., nos produtos analisados.

\section{Escherichia coli}

O teste de inoculação de colônia suspeita em ágar peptona-ferro visa verificar se a bactéria produz ou não de gás sulfídrico $\left(\mathrm{H}_{2} \mathrm{~S}\right)$ e no ágar eosina-cloreto

TABELA 8. Resultados obtidos na fase confirmatória para Salmonela sp.

\begin{tabular}{lccccc}
\hline & $\begin{array}{c}\text { Ágar } \\
\text { TSI }\end{array}$ & $\begin{array}{c}\text { Lisina } \\
\text { descarboxilase }\end{array}$ & Citrato & Urease & Lactose \\
\hline Castanha da Índia - lote 1 & positivo & positivo & negativo & positivo & negativo \\
Maracujá - lote 1 & negativo & positivo & negativo & positivo & positivo \\
Unha de gato & positivo & positivo & negativo & negativo & positivo \\
\hline
\end{tabular}

de metiltionínio, se há o crescimento de colônias pretas, esverdeadas e brilhantes. A amostra de Agaragar (lote 1), produziu gás e não foi evidenciado o crescimento de colônias pretas, esverdeadas e brilhantes, excluindo-se a possibilidade da presença de Escherichia coli, não sendo necessário a realização dos testes confirmatórios.

\section{CONCLUSÃO}

Os resultados obtidos mostraram que há presença microrganismos nas amostras, entretanto, em nenhuma delas, o valor de UFC g ${ }^{-1}$ ultrapassou o limite estabelecido para fitoterápicos na Farmacopéia Britânica (2005), tanto para bactérias como para fungos.

O procedimento de irradiação pode levar a diminuição na carga microbiológica nas amostras, o que auxilia no controle microbiológico das mesmas, no entanto não foi amplamente utilizado pelas empresas que manufaturaram as drogas vegetais analisadas neste trabalho.

O teste de pesquisa e identificação de patógenos mostrou que não havia a presença de 
Pseudomonas aeruginosa, Salmonella sp., Staphylococcus aureus e Escherichia coli, nas amostras analisadas.

\section{REFERENCIA}

ANVISA. Agência Nacional de Vigilância Sanitária. Resolução RDC no 67, de 08 de outubro de 2007. Boas práticas de manipulação de medicamentos para uso humano em farmácias. Diário Oficial da União, Brasília, 2006.

ANVISA. Agência Nacional de Vigilância Sanitária. Resolução RDC no 14, de 31 de março de 2010. Dispõe sobre o registro de Medicamentos Fitoterápicos. Diário Oficial da União, Brasília, 2010.

BRASIL. Ministério da Saúde. Secretaria Nacional de Vigilância Sanitária. Diretoria Colegiada. Resolução n. 48 de 16 de março de 2004. Diário Oficial, Brasília, DF, 18 de março de 2004. Seção 1, v.53, p.39-41.

BRITISH PHARMACOPOEIA. London: Her Majesty's Stationery Office, 2005. 1 CD-ROM.

BUGNO, A. et al. Avaliação da contaminação microbiana em drogas vegetais. Revista Brasileira de Ciências Farmacêuticas, v.41, n.4, p.491-7, 2005. CFF - CONSELHO FEDERAL DE FARMÁCIA. Estabilidade dos medicamentos após abertura. Pharmacia Brasileira, n.3, p.49-50, 2005.

FARMACOPÉIA BRASILEIRA. 4.ed. São Paulo: Atheneu, 1988.

FURLANETO, L.; MARINS, V.D.; ENDO, R. Qualidade microbiológica de drogas vegetais comercializadas nas ruas da cidade de Londrina/PR e seus infusos. Saúde em Revista, v.5, n.10, p.49-52, 2003.

MELO, J.G. et al. Qualidade de produtos a base de plantas medicinais comercializados no Brasil: castanha-da-índia (Aesculus hippocastanum L.), capim-limão (Cymbopogon citratus (DC.) Stapf.) e centela (Centella asiatica (L.) Urban). Acta Botânica Basílica, v.21, n.1, p.27-36, 2007.

PINTO, T.J.A; KANEKO, T.M.; OHARA, M.T. Controle biológico de qualidade de produtos farmacêuticos, correlatos e cosméticos. 2.ed. São Paulo:Editora Atheneu, 2003. 325p.

ROCHA, L.O.; SOARES, M.M.S.R.; CORREAA, C.L. Análise da contaminação fúngica em amostras de Cassia acutifolia Delile (sene) e Peumus boldus (Molina) Lyons (boldo-do-Chile) comercializadas na cidade de Campinas, Brasil. Revista Brasileira de Ciências Farmacêuticas, v.40, n.4, p.521-7, 2004.

SATOMI, L.C.; SORIANI, R.R.; PINTO, T.J.A. Descontaminação de drogas vegetais empregando irradiação gama e óxido de etileno: aspectos microbianos e químicos. Revista Brasileira de Ciências Farmacêuticas, v.41, n.4, p.445-50, 2005 SOUSA, A.L. et al. Determinação do teor de omeprazol por cromatografia líquida de alta eficiência (CLAE) em matérias-primas e produtos acabados. Revista Eletrônica de Farmácia, v.2, n.2, supl., p.206-9, 2005. SOUZA, T.P.; LIONZO, M.I.Z.; PETROVICK P.R. Avaliação da redução da carga microbiana de droga vegetal através do processamento tecnológico: decocção e secagem por aspersão. Revista Brasileira de Farmacognosia, v.16, n.1, p.94-8, 2006. 